\title{
ENTITLEMENT, EPISTEMIC RISK, AND SCEPTICISM
}

\author{
Luca Moretti \\ University of Aberdeen \\ 1.moretti@abdn.ac.uk
}

Final Draft

\begin{abstract}
Crispin Wright maintains that the architecture of perceptual justification is such that we can acquire justification for our perceptual beliefs only if we have antecedent justification for ruling out any sceptical alternative. Wright contends that this principle doesn't elicit scepticism, for we are non-evidentially entitled to accept the negation of any sceptical alternative. Sebastiano Moruzzi has challenged Wright's contention by arguing that since our non-evidential entitlements don't remove the epistemic risk of our perceptual beliefs, they don't actually enable us to acquire justification for these beliefs. In this paper I show that Wright's responses to Moruzzi are ineffective and that Moruzzi's argument is validated by probabilistic reasoning. I also suggest that Wright couldn't answer Moruzzi's challenge without weakening the support available for his conception of the architecture of perceptual justification.
\end{abstract}

Keywords: epistemic entitlement; epistemic risk; perceptual justification; scepticism; Crispin Wright; Roger White, Duncan Pritchard.

\section{Introduction}

Some of Crispin Wright's ideas have been playing a pivotal role in recent epistemological conversation. Wright maintains that the architecture of perceptual justification is such that we can acquire justification for our perceptual beliefs only if we have antecedent justification for ruling out any sceptical alternative. He contends that this fact doesn't elicit scepticism, for we are nonevidentially entitled to accept the negation of any sceptical alternative. Sebastiano Moruzzi has challenged Wright's contention by arguing that since our non-evidential entitlements don't remove the epistemic risk of our perceptual beliefs, they don't actually enable us to acquire justification for these beliefs. In this paper I show that Wright's responses to Moruzzi are ineffective and that Moruzzi's argument is validated by probabilistic reasoning. I also suggest that Wright couldn't answer Moruzzi's challenge without weakening the support available for his conception of the architecture of perceptual justification. 
This is the paper's structure: in $§ 2$ I detail Wright's conception of the architecture of perceptual justification and Wright's entitlement theory. In §3 I review Moruzzi’s objection. In §4 I criticize Wright's responses to Moruzzi. In §5 I argue that Moruzzi’s objection is validated by Bayesian reasoning. In $§ 6$ I draw my conclusions.

\section{Wright's epistemology of perception}

Wright (2004, 2007 and 2014) contends that the architecture of perceptual justification ${ }^{1}$ is such that: ${ }^{2}$

(PJ) A subject S's experience as if $p$ gives $\mathrm{S}$ (defeasible) justification for believing $p$ only if $\mathrm{S}$ has antecedent justification for accepting $\sim s h$, where $\sim_{s h}$ is the logical negation of any sceptical alternative $\mathrm{e}^{3} s h$ to $p .^{4}$

(PJ) raises at least two concerns. To begin with, it looks at odds with everyday epistemic practices; one may thus doubt that $(\mathrm{PJ})$ is true. Ordinarily, the reasons we attribute to ourselves or others for holding perceptual beliefs make no reference to sceptical alternatives. Imagine you have an experience as if the cat is on the mat. You would normally answer the question 'What reason do you have to believe that the cat is on the mat?' by saying 'I see it'. Responding 'I see it and have independent reason to rule out that I'm deceived by the Matrix' would appear out-of-place (cf. Pryor 2000 and McGrath 2013).

The second concern is that (PJ) prompts perceptual scepticism (cf. Pryor 2000 and Schiffer 2004). Consider a subject $\mathrm{S}$ experiencing as if $(P)$ the cat is on the mat. Suppose $S H$ is the

\footnotetext{
${ }^{1}$ By 'justification' I will always mean propositional (rather than doxastic) justification.

${ }^{2}$ Epistemic conservatives like White (2006) and Neta (2010) defend similar principles.

${ }^{3}$ By 'sceptical alternative' I refer to global sceptical hypotheses like the Cartesian demon scenario or the Matrix scenario.

${ }^{4}$ (PJ) is normally attributed to Wright (see for instance White 2006, Silins 2007, Neta 2010 and Silva 2010). Wright seems sometimes to endorse an alternative principle, according to which S's experience as if $p$ gives $\mathrm{S}$ justification for claiming that $S$ has justification for believing $p$ only if S has antecedent justification for accepting $\sim s h$. In this paper I criticize Wright interpreted as a supporter of (PJ). For discussion about these two alternative readings of Wright's conception of the structure perceptual justification see McGlynn (2017).
} 
proposition that $P$ is false but the Matrix makes $S$ hallucinate as if $P .^{5}$ The sceptic may adduce (PJ) to argue that S's experience as if $P$ gives $\mathrm{S}$ justification for believing $P$ only if $\mathrm{S}$ has antecedent justification for accepting $\sim S H$. The sceptic will insist that $S$ cannot have this antecedent justification. For any a posteriori evidence S might happen to possess can be conjectured to be in turn a hallucinatory state caused by the Matrix. Furthermore, S doesn't have a priori evidence for $\sim S H$. So S has no evidence justifying her acceptance of $\sim S H$. The sceptic will conclude that S's experience as if $P$ cannot justify S's belief that $P$ and - by generalizing this example - that S's experiences cannot justify any of S's perceptual beliefs.

To address the first concern, Wright has argued that the epistemological views that disallow (PJ), like Pryor (2000 and 2004)'s dogmatism, are in various ways problematic ${ }^{6}$ (cf. Wright 2007). The only direct argument — and I think the most forceful case — for the truth of $(\mathrm{PJ})$ is nonetheless a Bayesian one due to White (2006), who defends a view of the architecture of perceptual justification similar to Wright's. Let me outline White's argument, as I will use it later on. White adopts an entrenched model that construes epistemic justification as rational confidence. Let Pr be a probability function interpreted subjectively. $\operatorname{Pr}(p)$ expresses S's rational confidence that $p \cdot \operatorname{Pr}(p \mid q)$ expresses S's rational confidence that $p$ conditional on S's learning $q$. Suppose $E$ is the proposition that $\mathrm{S}$ has an experience as if $(P)$ the cat is on the mat, and $S H$ is the proposition that $P$ is false but the Matrix makes $\mathrm{S}$ hallucinate as if $P$. Since $S H$ entails $E$, if $\mathrm{S}$ learns $S H$, S must be certain that $E$. Hence $\operatorname{Pr}(E \mid S H)=1$. Since S shouldn't expect to experience as if the cat on the mat, $\operatorname{Pr}(E)<1$. Thus $\operatorname{Pr}(E \mid S H)>\operatorname{Pr}(E)$. This inequality implies that $\operatorname{Pr}(\sim S H \mid E)<\operatorname{Pr}(\sim S H)$. Furthermore, since $P$ entails $\sim S H, \operatorname{Pr}(P \mid E) \leq \operatorname{Pr}(\sim S H \mid E)$. The last two inequalities imply by transitivity that $\operatorname{Pr}(P \mid E)<\operatorname{Pr}(\sim S H)$. This formula says that if S learns $E$, S's confidence in $P$ must remain strictly smaller than S's prior confidence in $\sim S H$. Thus, S's learning $E$ can make $S$ rationally confident of $P$ 's truth only if S is antecedently rationally confident of $\sim S H$ 's truth. This shows that S's experiencing as if $P$ can give

\footnotetext{
${ }^{5}$ I use small letters for propositional variable and capital letters for propositional constants.

${ }^{6}$ For instance, they would produce easy justification and infringe probability principles.
} 
S justification for believing $P$ only if $\mathrm{S}$ has antecedent justification for accepting $\sim S H$ (cf. 2006 :

534-534). This argument can be reformulated to apply to any perceptual proposition $p$, any proposition $e$ stating that $\mathrm{S}$ experiences as if $p$, and any correlated sceptical alternative $s h$. The conclusion is that

(PC) $\operatorname{Pr}(p \mid e)<\operatorname{Pr}(\sim s h)$.

(PC) vindicates $(\mathrm{PJ})$.

Although Wright often construes epistemic justification as rational confidence (see for instance 2014: 233-234), he hasn't explicitly adduced (PC) to support (PJ). Wright (2007: 42) has nevertheless levelled a Bayesian objection to Pryor's dogmatism consisting of a variant or incomplete version of White's argument. ${ }^{7}$ So Wright would endorse this argument. Note that (PJ) takes S's evidence to be S's experience as if $p$, whereas (PC) takes S's evidence to be S's reflective belief that $(e)$ she has an experience as if $p$. One could question whether S's belief that $e$ constitutes a reliable model of S's experience as if $p$ in epistemic evaluations (cf. Moretti 2015). Wright nevertheless doesn't distinguish between one's experience and one's reflective belief that one has an experience when discussing scepticism (cf. 2002, 2004, 2007 and 2014). Wright seems to share White (2006: 353) and Silins (2007: 120n17)'s conviction that one's experiences and one's reflective beliefs about one's experiences are interchangeable in most epistemic contexts.

To address the second concern — the worry that (PJ) elicits scepticism-Wright $(2004,2007$ and 2014) admits that there is no or very little evidence in support of propositions like $\sim S H$. Yet he argues that there exists a type of non-evidential justification — called by him entitlement - that all rational subjects possess by default for accepting the logical negation of any sceptical alternative. ${ }^{8}$ Acceptance is an attitude more inclusive than belief. Belief entails acceptance but the reverse is

\footnotetext{
${ }^{7}$ The objection — which Wright attributes to Schiffer (2004) — says that the dogmatist is committed to maintaining that, for any $p$ and $e, \operatorname{Pr}(p \mid e)$ must be sufficiently high, but that she cannot provide a justification for the required value of $\operatorname{Pr}(\sim s h)$ and other priors.

${ }^{8}$ More generally, for Wright, we are entitled to accept certain hinge propositions inclusive of these negations.
} 
false. Wright acknowledges that an entitlement to accept $\sim S H$ is not one to believe $\sim S H$. For it is dubious that S could rationally believe a proposition with no or very little evidence for its truth (cf. 2004: 176). This thesis is widely held in epistemology nowadays (cf. Chignell 2017: §5). Wright suggests that the type of acceptance licensed by S's entitlements is rational trust, or a very similar attitude (cf. 2004: 194).

Wright's thesis that we are entitled to accept propositions like $\sim S H$ has attracted criticism of various types (see McGlynn 2017 for a survey). For instance, some authors contend that what Wright calls entitlement isn't epistemic justification (cf. Pritchard 2005 and Jenkins 2007). Wright (2014) has made a good effort to address most of these objections. In the following, I concentrate on an important criticism made in discussion by Sebastiano Moruzzi (cf. Wright 2004: 208n 26), which I think hasn't properly been addressed so far.

\section{Moruzzi's objection}

Moruzzi's challenge exploits a notion of epistemic risk introduced by Wright himself. Wright emphasizes that whenever S accepts a proposition $p$ the truth of which is insufficiently supported by her evidence, S runs a risk - the one of accepting a proposition as true that is actually false. Since this type of risk is incompatible with S's justifiedly believing and knowing $p$, Wright calls it epistemic risk. More accurately, the relation that Wright claims to hold between epistemic risk and epistemic justification is this: S's accepting $p$ is epistemically risky if and only if S's evidence doesn't suffice to justify her believing $p$. Note that S's accepting $p$ when $p$ is insufficiently supported by evidence would be epistemically risky even if S's acceptance were justified by an entitlement to $p$. This is so because this entitlement of S would not rest on or produce any evidence for $p$ 's truth. For example, Wright (2004: 208-209) acknowledges that S's accepting $\sim S H$ would be epistemically risky despite S's entitlement to $\sim S H$. 
Moruzzi's objection rests on the intuition that for any $p$ and correlated sceptical alternative $s h$, the epistemic risk of $\sim s h$ transmits to $p$. The objection says that since $\mathrm{S}$ 's accepting $\sim s h$ is epistemically risky despite S's entitlement to $\sim s h, \mathrm{~S}$ 's accepting $p$ is also epistemically risky despite S's experiencing as if $p$. Consequently, S's justification for $p$ depending on S's experience as if $p$ (if any) cannot sustain $\mathrm{S}$ 's belief that $p$. If this is true, $\mathrm{S}$ 's entitlements might permit $\mathrm{S}$ to trust perceptual propositions, but they cannot enable $\mathrm{S}$ to believe them. The sceptical challenge invited by $(\mathrm{PJ})$ would remain unanswered in this case.

\section{Analysis of Wright's responses}

Wright (2004) and Wright (2014) have respectively given Moruzzi's objection two different responses. In both papers Wright insists that no epistemic risk transmits from $\sim s h$ to $p$ but the reasons he adduces go in opposite directions. I now criticize both responses in turn.

Wright (2004: 207-209) argues that the intuition that the epistemic risk of $\sim s h$ transmits to $p$ is flawed because it relies on a false assumption.

Since the risk involved is that of acceptance of a proposition without knowledge of or evidential [justification] for its truth, the idea that the risk transfers from $[\sim s h]$ to $p$ is just the contrapositive of the idea that knowledge and evidential [justification] transmit from $p$ to $[\sim s h]$. So interpreted, then, the worry about [epistemic risk] is just a version of the discredited assumption that [justification] is unrestrictedly transmissive. (2014: 229)

Let's unpack this condensed explanation. The expression 'evidential justification' refers to justification depending on evidence (i.e. a belief or an experience) sufficient to sustain belief. Recall that $p$ entails $\sim s h$. Wright $(2002,2003$ and 2007) has argued that evidential justification doesn't always transmit across entailment. S's justification for $p$ resting on evidence $e$ transmits across the entailment from $p$ to $q$-according to Wright - just in case (i) S has justification for believing $p$ from $e$, (ii) $\mathrm{S}$ knows that $p$ entails $q$, and (iii) $\mathrm{S}$ has justification for believing $q$ in virtue of the truth 
of both (i) and (ii). Wright claims that (iii) remains unsatisfied whenever S's acquiring justification for believing $p$ from $e$ requires $\mathrm{S}$ to have antecedent justification for accepting $q$. Suppose for instance $\mathrm{S}$ has two identical copies, $H$ and $H^{*}$, of Hamlet. $O$ is the disjunctive proposition that $t$ is book looks like $H$ or $H^{*}$. $A$ is the proposition the book is actually $H . B$ is the proposition that the book is not $H^{*}$. S's acquiring justification for believing $A$ from $O$ requires $\mathrm{S}$ to have antecedent justification for accepting $B$. Suppose that this requirement is met and that (i) $\mathrm{S}$ learns $O$ thereby acquiring justification for believing $A$. Also suppose that (ii) $\mathrm{S}$ knows that $A$ entails $B$. In these circumstances - according to Wright (2002, 2003 and 2007) - it is intuitive that S cannot acquire justification for believing $B$ in virtue of the truth of (i) and (ii). So (iii) is false. This is a case of transmission failure. If $(\mathrm{PJ})$ is true, the entailment from $p$ to $\sim s h$ should also instantiate transmission failure, for S's acquiring justification for believing $p$ from her experience as if $p$ requires $\mathrm{S}$ to possess antecedent justification for accepting $\sim_{s h}(\mathrm{cf}$. Wright 2007).

My best interpretation of Wright's passage quoted above is this: if you have the impression that the epistemic risk of $\sim s h$ transmits to $p$, this is only because you mistakenly presuppose that evidential justification is unrestrictedly transmissive so that any evidential justification for $p$ must transmit to $\sim s h$. In fact, if you presuppose this and realize that S doesn't have evidential justification for $\sim s h$ because $\sim s h$ is epistemically risky, you are bound to conclude — on pain of contradiction - that $\mathrm{S}$ doesn't have justification for believing $p$ either, which means that $p$ is also epistemically risky.

This diagnosis is misguided because it confuses S's justification for $\sim s h$ that $S$ acquires upon experiencing as if $p$ with S's antecedent justification for $\sim$ sh resting on $S$ 's mere entitlement to $\sim s h$. Suppose you endorse both $(\mathrm{PJ})$ and Wright's entitlement theory but presuppose that evidential justification is unrestrictedly transmissive. Imagine you realize that $\mathrm{S}$ lacks antecedent justification for believing $\sim s h$. Given your presupposition, you can still conclude without 
contradiction that $\mathrm{S}$ has justification for believing $\sim s h$-namely, evidential justification transmitted to $\sim s h$ from $p$. In fact note that this justification transmitted to $\sim_{s h}$ is not antecedent justification for believing $\sim s h$, which $\mathrm{S}$ lacks, but justification that $\mathrm{S}$ is supposed to acquire when she experiences as if $p$ and deduces $\sim s h$ from $p$. Since you can conclude that $\mathrm{S}$ has evidential justification for $\sim s h$, you aren't bound to maintain that $\mathrm{S}$ lacks evidential justification for $p$, so that $p$ is epistemically risky. This shows that the intuition that $\sim_{s h}$ 's epistemic risk transmits to $p$ doesn't depend on presupposing (mistakenly or not) that evidential justification is unrestrictedly transmissive.

Wright (2014: 228-235) has given Moruzzi's objection a novel response. It says that no epistemic risk transmits from $\sim s h$ to $p$ because $\sim_{s h}$ is not epistemically risky after all. This response too appears flawed to me. ${ }^{9}$

Although Wright (2014) endorses (PJ), in this paper he concedes that evidential justification—when suitably qualified—-transmits from $p$ to $\sim s h$. Wright contends that (PJ) blocks the transmission of two types of justification. Firstly, no justification transmitted from $p$ to $\sim_{s h}$ can be a first-time justification for accepting $\sim s h$. For $\mathrm{S}$ can acquire justification for $p$ from experiencing as if $p$ only if $\mathrm{S}$ has already justification for accepting $\sim_{S h}$. Furthermore, no justification transmitted to $\sim s h$ from $p$ can raise $\sim s h$ 's 'rational credibility'. For 'whatever limit there was to the rational credibility of $\left[\sim_{S h}\right]$ as an object of trust..., it remains as an upper bound on its rational credibility as an object of belief based on the appearance that $[p]$ ' (2014: 233). ${ }^{10}$ Wright argues that, nevertheless, $(\mathrm{PJ})$ doesn't debar evidential justification from transmitting from $p$ to $\sim s h$ if the justification is neither a first time justification for accepting $\sim_{s h}$ nor one that boosts $\sim_{s h}$ 's credibility. Drawing from Hawthorne (2004: 39-40) and McGlynn (2014), Wright contends that this transmission can persuasively take place through a two-stage inference: suppose $\mathrm{S}$ has evidential

\footnotetext{
${ }^{9}$ I put forward this diagnosis more hesitantly, as I found Wright's discussion less clear in this case.

${ }^{10}$ This claim is vindicated by White's model, as $\operatorname{Pr}(\sim s h \mid e)<\operatorname{Pr}(\sim s h)$.
} 
justification for $p$. This justification will first transmit to the disjunction $p \mathrm{v} \sim s h$, entailed by $p$. This is so, for Wright, because it is compelling that any justification for believing either disjunct of a disjunction is by itself justification for believing the disjunction. S's justification for $p \mathrm{v} \sim s h$ will then transfer to $\sim s h$, which is a priori equivalent to the disjunction (cf. 2014: 231-233). Wright thinks that since $\mathrm{S}$ is entitled to $\sim s h, \mathrm{~S}$ will acquire justification for believing $p$ from her experience as if $p$, and this evidential justification will transfer to $\sim s h$. This would show that Moruzzi's challenge ultimately dissolves, as 'we no longer have the assumption in place that there can be no evidential [justification] for [ $\sim s h]^{\prime}(2014: 235) .{ }^{11}$ In other words, we no longer have the assumption in place that $\sim s h$ is epistemically risky.

This response to Moruzzi puts the cart before the horse. Wright contends that evidential justification can transmit from $p$ to $\sim s h$. Suppose his explanation is correct. Evidential justification will transmit from $p$ to $\sim s h$ only if $\mathrm{S}$ does have evidential justification for $p$ in the first instance. But Moruzzi's objection was precisely that S couldn't have this justification. Given that S's entitlement to $\sim s h$ cannot remove $\sim s h$ 's epistemic risk, and this risk-according to Moruzzi-transmits to $p, p$ must be epistemically risky when $\mathrm{S}$ experiences as if $p$. So S's justification for $p$ based on S's experience as if $p$ (if any) will be unable to sustain S's belief that $p$. Hence, there will be no evidential justification to be transmitted from $p$ to $\sim_{s h}$ in the first instance.

\section{Transmission of epistemic risk}

Although Wright's responses to Moruzzi are ineffective, we cannot conclude yet that Moruzzi's objection goes through. For Moruzzi's claim that $\sim_{s h}$ 's epistemic risk transmits to $p$ hasn't been substantiated. In this section I will show that this claim can be validated through (PC) once the

\footnotetext{
${ }^{11}$ Wright maintains that (what he calls) the leaching problem dissolves, but Moruzzi's challenge is the only version of the leaching problem analysed in his paper (cf. 2014: 228-229).
} 
standard probabilistic account of risk is presupposed. Since this standard account has recently been challenged, I would like to dwell on this issue before proceeding any further.

The term 'risk' is customarily taken to refer to the probability of an unwanted event, where this probability is estimated on a relevant body of evidence. This usage is for instance exemplified by the statement that, on the current medical evidence, the risk that a smoker's life is shortened by some smoking-related disease is about $1 / 2$ (cf. Hansson 2018). ${ }^{12}$ It might look self-evident that our judgements about risk track probability. Pritchard (2015 and 2016) has nevertheless challenged this thesis with an apparent counterexample.

(BOMB)

Case 1: An evil scientist has rigged up a large bomb, which he has hidden in a populated area. If the bomb explodes, many people will die. There is no way of discovering the bomb before the time it is set to detonate. The bomb will only detonate, however, if a certain set of numbers comes up on the next national lottery draw. The odds of these numbers appearing is fourteen million to one. It is not possible to interfere with this lottery draw.

Case 2: An evil scientist has rigged up a large bomb, which he has hidden in a populated area. If the bomb explodes, many people will die. There is no way of discovering the bomb before the time it is set to detonate. The bomb will only detonate, however, if a series of three highly unlikely events obtains. First, the weakest horse in the field at the Grand National, Lucky Loser, must win the race by at least ten furlongs. Second, the worst team remaining in the FA Cup draw, Accrington Stanley, must beat the best team remaining, Manchester United, by at least ten goals. And third, the queen of England must spontaneously choose to speak a complete sentence of Polish during her next public speech. The odds of this chain of events occurring are fourteen million to one. It is not possible to interfere with the outcomes of any of the events in this chain. (Pritchard 2015: 441)

Pritchard observes that although the unwanted event — the bomb's detonating — is equally likely in both cases, its risk in Case 1 is intuitively higher than in Case 2. For we have the feeling that, despite the detonation triggering events have equal chances in both cases, the detonation triggering event in Case 1 could happen more easily than the detonation triggering event in Case 2. All that is

\footnotetext{
${ }^{12}$ A refinement of this conception, adopted in professional risk management and economics, interprets 'risk' as referring to the expectation value of a possible negative event, which is the product of the event's probability and some measure of its severity (cf. Hansson 2018). To avoid sterile complications, I follow Pritchard (2015 and 2016) and Bricker (2018) in setting aside this more technical notion.
} 
needed for the detonation triggering event in Case 1 to materialize is simply that a few numbered balls be extracted in a particular sequence. In contrast, the detonation triggering event in Case 2 could take place only if many weird things took place all together.

To explain our intuitions about risk elicited by cases like (BOMB), Pritchard develops a modal conception of risk alternative to the probabilistic one. Pritchard explicates the notion of easy possibility by exploiting the familiar idea that possible worlds are more or less close to the actual world in the sense that they are more or less similar to it. He submits that an event could easily happen just in case the closest worlds in which it takes place are very similar to the actual world, and that an event could happen more easily than another just in case the closest worlds in which it takes place are more similar to the actual one than the closest worlds in which the other event occurs. The detonation triggering event in Case 1 could happen more easily than the detonation triggering event in Case 2 because the closest worlds in which it takes place are more similar to the actual one than the closest worlds in which the other event occurs.

In this account, the degree of risk of an unwanted event is proportional to its modal distance from to the actual world, rather than its likelihood. Precisely, the degree of risk of a proposition $p$ describing a given event is determined by the degree of closeness to the actual world of the closest worlds in which $p$ is true: the closer these worlds, the higher the risk. Suppose now that $P$ states that the bomb is detonating. Since $P$ is true in very close worlds in Case 1, but only in remote worlds in Case 2, $P$ proves more risky in Case 1 than in Case 2.

Bricker (2018) observes that Pritchard's modal account, if working at all, would also explain cases in which our judgements seem to track probability, since probability and modal ordering are often correlated. (For example, note that your serious bodily injuring yourself from playing chess is both a very improbable event and one that happens only in very remote worlds.) The modal account of risk would thus be capable of handling cases that the probabilistic account cannot handle but also cases that appear to suggest that risk tracks probability. 
It is far from clear, however, that Pritchard's account constitutes "the correct analysis of risk" or that it should be preferred to the probabilistic account. Pritchard's reasons to reject the probabilistic account primarily hinge on our intuitive judgments about risk elicited by (BOMB). Pritchard thinks that the best explanation of why we make these judgments is that we apply his modal notion of risk, which we would implicitly possess. But this argument can be questioned. The judgments elicited by (BOMB) might simply stem from our heuristics, cognitive biases, or similar psychological factors. So these judgments might be no evidence that our pre-theoretical conception of risk is akin to that outlined by Pritchard. For instance, note that the degree of probability of the detonation triggering event in Case 2 has been stipulated - no explanation of how it has been worked out is offered. Since the numerical value supplied by Pritchard looks terribly far-fetched, it is perhaps natural that we (or our sub-personal cognitive systems) tend to ignore that piece of information. If this is true, psychology can offer various explanations of why we end up judging that the unwanted event is less risky in Case 2 than in Case 1. Some explanations are compatible with the probabilistic account of risk. For instance, Kahneman and Tversky (1974) have shown that there is a positive correlation between how easily a subject simulates (i.e. mentally pictures) an event and how probable she estimates that the event is. Note that the detonation triggering event of Case 2 is far less easy to simulate than the detonation triggering event of Case 1.

The modal account of risk has counterintuitive consequences that the probabilistic account doesn't imply. Suppose you are about to flip a coin C that you know to be fair, and you have bet $£ 100$ on heads, while your opponent has bet $£ 100$ on tails. If you win, you get $£ 100$, otherwise you lose $£ 100 .{ }^{13}$ It is intuitive that before seeing the outcome, you should judge the proposition that $(P)$ C lands tails, to be considerably risky. The probabilistic account explains why: given your evidence, the chance that the unwanted event that $P$ takes place is $1 / 2$. The modal account provides an alternative explanation: your evidence allows you to conclude that the possible worlds in which $P$ is true are

\footnotetext{
${ }^{13}$ If don't value money, replace it with anything else you value.
} 
very close. Imagine now that $\mathrm{C}$ lands heads, and that you see it. In light of your new evidence, you should no longer judge $P$ to be is risky to any extent. This is straightforwardly explained by the probabilistic account: the new evidence indicates that $P$ 's chance has dropped to zero. However, on the modal account you are still rationally required to take $P$ to be risky to some degree. For your new evidence still allows you to conclude that the worlds in which $P$ is true are very close. (In those worlds you don't see that $\mathrm{C}$ lands heads - you see it lands tails. But this doesn't make them remote worlds.) More generally, on the modal account, any event that could have easily happened but is known not to have happen must be taken to be risky to some extent. This doesn't match the intuitive idea of risk. As Hansson (2005: 68) has emphasized, 'Risks are always connected to lack of knowledge... if we know that no explosion will take place, then there is no reason... to talk about risk'.

Producing a thorough assessment of the modal account of risk would take us too far afield. Let me only add that Pritchard (2015 and 2016) has attempted to defend his account by showing that it can illuminate (BOMB) but also by describing independent supporting evidence available in psychology and cognitive sciences. Bricker (2018) has nonetheless adduced alternative empirical evidence that looks incompatible with Pritchard's modal account. Importantly, Bricker has also detailed an imaginary case similar to (BOMB) that prompts judgments about risk that appear unexplainable by both the modal account and the probabilistic account. Thus, this interesting dispute is far from being settled.

My view is that to investigate whether epistemic risk transmits, we don't need to produce "the correct analysis of risk". There might be no such analysis - perhaps our pre-theoretical conception of risk is partly incoherent or indeterminate and admits of more than just one analysis or precisification. To investigate whether or not epistemic risk transmits, we only need to rely on a notion of risk sufficiently close to the one that Wright and Moruzzi presuppose in their dispute. 
There is no reason to think that Wright and Moruzzi adopt a conception of risk different from the orthodox one, which is probabilistic.

It is also noteworthy that if Wright endorsed Pritchard's modal conception of risk, he would face a kind of conceptual incoherence. For he would have to acknowledge that there are many propositions the acceptance of which is epistemically risky but, simultaneously, not risky. To see this, remember that Wright holds that thanks to our entitlements to rule out all sceptical alternatives, our perceptual beliefs are normally justified. Wright is thus committed to taking the actual world to be broadly as it appears to be, and so to taking any sceptical conjecture $s h$ to be true only in remote possible worlds. Consider now any conjecture $s h$ of this type. If Wright adopted the modal conception of risk, he would need to acknowledge that although our best evidence cannot justify believing $\sim s h$, so that accepting $\sim s h$ is epistemically risky, accepting $\sim_{s h}$ is not risky. For $\sim_{s h}$ is false only in remote possible worlds. ${ }^{14}$

Let me now show that once the probabilistic account of risk is presupposed, Moruzzi's claim that epistemic risk transmits can be validated through (PC). Take any perceptual proposition $p$, a proposition $e$ stating that $\mathrm{S}$ experiences as if $p$, and any correlated sceptical alternative $s h$. The degree of risk that $\sim s h$ is false — expressed by $\operatorname{RS}_{\mathrm{F}}\left(\sim_{s h}\right)$ — can be identified with $\operatorname{Pr}(s h)$, where $\operatorname{Pr}$ is a probability function interpreted subjectively. ${ }^{15}$ The degree of risk that $p$ is false given $e-$ expressed by $\operatorname{RS}_{\mathrm{F}}(p \mid e)$ — can be identified with $\operatorname{Pr}(\sim p \mid e)$. Since $\operatorname{RS}_{\mathrm{F}}(\sim s h)=\operatorname{Pr}(s h)$ and $\operatorname{RS}_{\mathrm{F}}(p \mid e)=$ $\operatorname{Pr}(\sim p \mid e)$, it is easy to show that $(\mathrm{PC}) \operatorname{Pr}(p \mid e)<\operatorname{Pr}(\sim s h)$ is equivalent to:

(RS) $\operatorname{RS}_{\mathrm{F}}(p \mid e)>\operatorname{RS}_{\mathrm{F}}(\sim s h)$.

\footnotetext{
${ }^{14}$ I don't want to suggest that Pritchard's modal account of risk is epistemologically flawed or problematic because of this result. My view is that the modal account may harmonize with externalist epistemologies (like the one described in Pritchard 2016) but it appears incoherent with the internalist approach to justification and knowledge generally favoured by Wright.

${ }^{15}$ Risk is usually interpreted as referring to the objective probability or chance of an event. Nevertheless, objective probability can in principle be translated into subjective probability because, for every proposition $q$, any rational subject S must conform her degree of confidence in $q$ to the chance of $q$ once $\mathrm{S}$ knows this chance, in accordance with Lewis' Principal Principle.
} 
(RS) states that the degree of risk that $p$ is false given $e$ is strictly higher than the degree of risk that $\sim s h$ is false independent of $e .(\mathrm{RS})$ validates Moruzzi's claim that $\sim s h$ 's epistemic risk transmits to $p$. To see this, take $\boldsymbol{r}$ to be a threshold value of epistemic risk. In other words, suppose that whenever $\boldsymbol{r}$ is exceeded by a proposition, the risk that it is false is so high that S's believing that proposition would be unjustified. $(\mathrm{RS})$ entails that if $\operatorname{Rs}_{\mathrm{F}}(\sim s h)>\boldsymbol{r}$, then $\operatorname{Rs}_{\mathrm{F}}(p \mid e)>\boldsymbol{r}$. That is to say, if S's accepting $\sim s h$ on the basis of a non-evidential entitlement (and so prior to learning $e$ ) is epistemically risky, S's accepting $p$ upon learning $e$ is also epistemically risky.

\section{Concluding remarks}

Since it is plausible that the epistemic risk of $\sim s h$ transmits to $p$, Wright's entitlement theory appears unable to neutralize the sceptical challenge arising from (PJ). Wright still has some space for manoeuvre though. He could try to argue that White's Bayesian model is unreliable or misleading. For instance, he might contend that probability calculus is ill-suited to model our rational confidence when we reflect on outlandish conjectures like those adduced by the sceptic (cf. Weatherson 2007). ${ }^{16}$ As already suggested, Wright could also challenge the assumption at the hart of White's model that one's experience and one's reflective belief that one has an experience are relevantly similar in terms of justifying power (cf. Moretti 2015). If responses like these were to succeed, however, Wright should drop the apparently convincing case for (PJ) made by White. One way or another, Wright's epistemology of perception would be endangered. ${ }^{17}$

\footnotetext{
${ }^{16}$ Weatherson (2007) argues that sceptical conjectures (and their negations) are uncertain rather than risky-in accordance with Keynes (1937)'s distinction - and that standard probability calculus cannot model uncertainty. ${ }^{17}$ I'm very grateful to Peter Brössel, Davide Fassio, Federico Luzzi, Matthew McGrath, Kevin Olivier, Tommaso Piazza, Jim Pryor, Martin Smith, Ulrich Stegmann, Stephan Torre, Crispin Wright and a Reviewer and an Associate Editor of this Journal for helpful criticism and comments upon drafts of this paper.
} 


\section{REFERENCES}

Bricker, A. M. 2018. 'Do judgements about risk track modal ordering?' Thought, 7: 200-208.

Chignell, A. 2017. 'The Ethics of Belief'. In E. N. Zalta (ed.), Stanford Encyclopedia of Philosophy. https://plato.stanford.edu/archives/spr2017/entries/ethics-belief/.

Jenkins, C. 2007. 'Entitlement and Rationality'. Synthese, 157: 25-45.

Hansson, S. O. 2005. 'The Epistemology of Technological Risk'. Techné: Research in Philosophy and Technology, 9: 68-80.

2018. 'Risk'. In E. N. Zalta (ed.), Stanford Encyclopedia of Philosophy.

https://plato.stanford.edu/archives/fall2018/entries/risk/

Hawthorne, J. 2004. Knowledge and Lotteries. Oxford: Clarendon Press.

Kahneman, D. and A. Tversky. 1974. 'Simulation heuristic'. In D. Kahneman, P. Slovic and A. Tversky (eds), Judgement Under Uncertainty: Heuristics and Biases, pp. 201-208. Cambridge, UK: Cambridge University Press.

Keynes, J. M. 1937. 'The General Theory of Employment'. Quarterly Journal of Economics, 51: 209-223.

McGlynn, A. 2014. 'On Epistemic Alchemy'. In D. Dodd and E. Zardini (eds), Scepticism and Perceptual Justification, pp. 173-189. Oxford: Oxford University Press.

2017. 'Epistemic Entitlement and the Leaching Problem'. Episteme, 14: 89-102.

McGrath, M. 2013. 'Dogmatism, Underminers and Skepticism'. Philosophy and Phenomenological Research, 86: 533-62.

Moretti, L. 2015. 'In defence of dogmatism'. Philosophical Studies, 172: 261-282.

Neta, R. 2010. 'Liberalism and Conservatism in the Epistemology of Perceptual Belief'. Australasian Journal of Philosophy, 88: 685-705. 
Pritchard, D. 2005. 'Wittgenstein's On Certainty and Contemporary Anti-Scepticism'. In D. MoyalSharrock and W. H. Brenner (eds), Readings of Wittgenstein's On Certainty, pp. 189-224. London: Palgrave MacMillan.

2015. 'Risk'. Metaphilosophy, 46:436-461.

2016. 'Epistemic Risk’. Journal of Philosophy, 113: 550-571.

Pryor, J. 2000. 'The Skeptic and the Dogmatist'. Nous, 34: 517-549.

'What's wrong with Moore's argument?' Philosophical Issue, 14, Epistemology: 349-378.

Schiffer, S. 2004. 'Skepticism and the vagaries of justified belief'. Philosophical Studies, 131: 525557.

Silins, N. 2007. 'Basic Justification and the Moorean Response to the Skeptic'. In T. S. Gendler and J. Hawthorne (eds), Oxford Studies in Epistemology Vol. 2, pp. 108-140. Oxford: Oxford University Press.

Silva. P. 2010. 'How to be Conservative: a Partial Defence of Epistemic Conservatism'. Australasian Journal of Philosophy, 91: 501-514.

Weatherson, B. 2007. 'The Bayesian and the dogmatist'. Proceedings of the Aristotelian Society, 107: 169-185.

White, R. 2006. 'Problems for dogmatism'. Philosophical Studies 131: 525-257.

Wright, C. 2002. '(Anti-)Sceptics Simple and Subtle: G. E. Moore and John McDowell'. Philosophy and Phenomenological Research, 65: 330-348.

2003. 'Some Reflections on the Acquisition of Warrant by Inference'. In S.

Nuccetelli (ed.), New Essays on Semantic Externalism and Self-Knowledge, pp. 57-77.

Cambridge, Mass.: MIT Press.

2004. 'On Epistemic Entitlement: Warrant for Nothing (and Foundations for Free?)'.

Proceedings of the Aristotelian Society, Supplementary, 78: 167-212. 
'Perils of Dogmatism'. In S. Nuccetelli (ed.), Themes from G. E. Moore: New Essays in Epistemology and Ethics, pp. 25-48. Oxford: Oxford University Press.

'On Epistemic Entitlement (II): Welfare State Epistemology’. In E. Zardini and D.

Dodd (eds.), Scepticism and Perceptual Justification, Ch. 10. New York: Oxford University Press. 